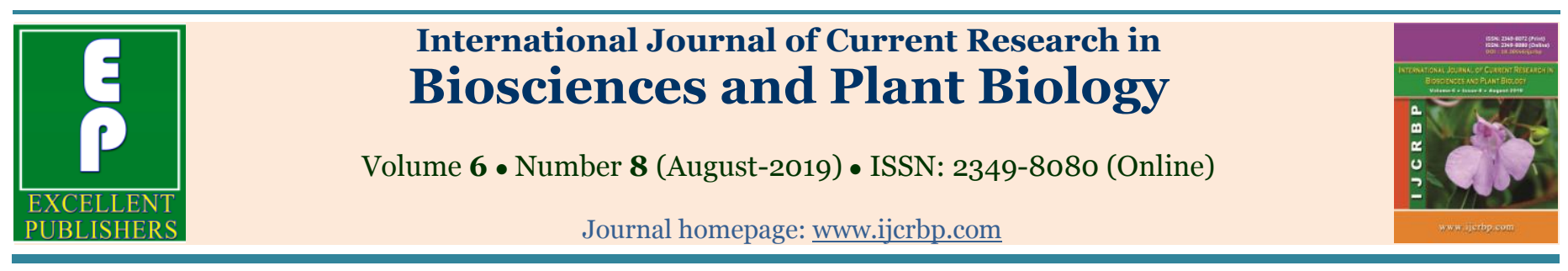

\title{
Mushrooms in Saudi Arabia (local and imported)
}

\author{
Syeda Fatima Manzelat*
}

Department of Biology, College of Science and Arts, Ad Darb, Jazan University, Saudi Arabia

*Corresponding author e-mail: drsyedafatima@hotmail.com

\begin{tabular}{ll}
\hline Article Info & ABSTRACT \\
\hline $\begin{array}{l}\text { Date of Acceptance: } \\
\text { 14 July 2019 }\end{array}$ & $\begin{array}{l}\text { Mushrooms the beautiful edible macrofungi are important medicinally and } \\
\text { nutritionally. The present study attempts to explore the locally grown mushrooms and } \\
\text { also the imported varieties. Nine different genera of mushrooms were collected from } \\
\text { Date of Publication: } \\
\text { o6 August 2019 }\end{array}$ \\
The nine genera were Agaricus, Agrocybe, Amanita, Boletus, Coprinus, Lepiota, \\
Keywords & $\begin{array}{l}\text { Pleurotus and Podaxis belonging to Basidiomycotina. Morchella was the only genus } \\
\text { belonging to Ascomycotina. The imported mushrooms from different countries mainly }\end{array}$ \\
\hline $\begin{array}{l}\text { Ascomycotina } \\
\text { Basidiomycotina }\end{array}$ & $\begin{array}{l}\text { Holland, Japan, Malaysia and Thailand are collected from local markets from Abha and } \\
\text { Mushrooms } \\
\text { Saudi Arabia }\end{array}$ \\
with different varieities like Silver creek and Portobello, Auricularia polytricha (Black \\
fungi), Cyclocybe aegerita (Yanagi Mushroom), Flamullina velutipes, Hypsizygus \\
tessellates (White Crab Mushroom), Lentinula edodes (Shiitake Mushroom), \\
Lyophyllum shimeji (Brown Shimeji), Pleurotus or Oyster Mushroom with two species \\
Pleurotus eryngii and Pleurotus ostreatus. Agaricus was the most common and \\
predominant genera both as local and imported variety. Photographs of the mushrooms \\
were taken and also the cross sections were studied. The structure of the gills is \\
depicted by the spore print taken on the filter paper. More mushroom farms are \\
required to be established so that they can be grown locally. As they are primary \\
decomposers of organic matter they are also responsible for protection of environment \\
and hence agents for controlling pollution. They are also eco friendly agents for \\
recycling the waste.
\end{tabular}

\section{Introduction}

Mushrooms are the beautiful macrofungi belonging to the class Ascomycotina and Basidiomycotina. Majority of the mushrooms belong to Basidiomycotina. A total of 52 mushroom species belonging to Basidiomycota, while 4 species belong to Ascomycota (Benchawattananon, 2016). The plant body of mushrooms consists of thread like branched hyphae with a cap like fruiting body which has gills and basidiospores. The fruiting body of the mushrooms is found growing in beautiful shapes and bright colours ranging from $5 \mathrm{~cm}$ to $30 \mathrm{~cm}$ in diameter. They are found growing in a wide range of habitats like soil, wood, rice straw, in the fields etc. Some varieties are edible and delicious to eat while others are deadly poisonous.

They have nutritional and medicinal values as they boost the immune system, good for bladder health and are also a good source of vitamins and 
antioxidants. For millennia, epigeous macrofungi (mushrooms) and hypogeous macrofungi (truffles) were considered as precious food in many cultures based on their high nutritional value and characterized by pleasant aroma. In African and Middle Eastern cultures, macrofungi have long history as high nutritional food and were widely applied in folk medicine (El Enshasy et al., 2013). Additionally, truffles have been used to promote health and to prevent and to treat several diseases. They have been reported to possess antiinflammatory, immunosuppressing, and anticarcinogenic properties antioxidant properties and antimicrobial activities This was based on the fact that they are rich source for proteins, amino acids, fatty acids, fiber, minerals, vitamins, terpenoids, sterols, flavor compounds, and carbohydrates as reported by many authors (El Enshasy et al., 2013).

Mushrooms contain high proportion of protein and low in calories and can replace meat. They can be used as fodder and fertilizers also. Cultivation of mushrooms can create job opportunities and thus has a positive impact on the economy of a country. Eating poisonous mushrooms can result in a range of symptoms, from a bad headache to gastro intestinal problems vomiting, fainting and also death. Iranian media say 15 die after eating wild mushrooms. Over 800 people suffer mushroom poisoning in Iran. At least 11 people have died in the country after eating toxic mushrooms (The Irish Times, 2018).
Mushrooms are cultivated in mushroom farms in different places of Saudi Arabia .As they are primary decomposers of organic matter they are responsible for protection of environment and hence act as agents for controlling pollution. Mushroom production is a potential biotechnological process wherein the waste plant materials or negative value crop residues can be converted into valuable food (Verma and Chauhan, 2017).

\section{Materials and methods}

\section{Materials}

Refrigerator, microscope, camera, gloves, polythene bags, containers, plastic bottles, masks, distilled water, formaldehyde solution, hand lens, tongs , forceps and needles, filter papers.

\section{Methods}

\section{Local varieties from Abha and Jizan}

The mushrooms are found growing at many places in Saudi Arabia hence can be collected easily by handpicking. Different sampling sites including mushroom farm were visited to collect the local varieties from Abha and Jizan regions which included Birk, Huraidha, Qahma, Ad Darb, Rijal Al Maa, Maraba Valley, Muhayil and Mount Souda from the two provinces (Fig. 1-A).
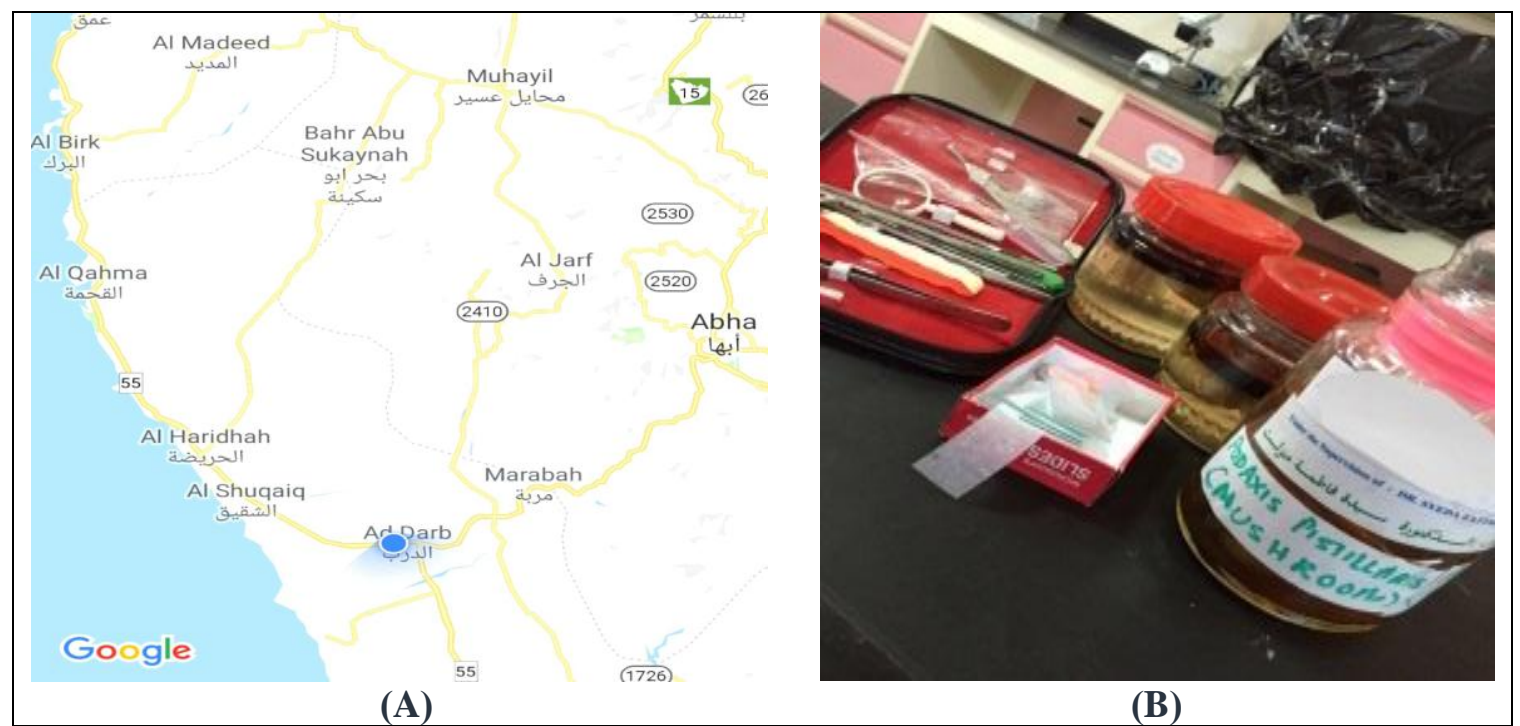

Fig. 1: (A) A map showing the sampling sites in Abha and Jizan (Source Google Maps).

(B) Preserved mushroom in the laboratory. 
Imported varieties were collected from markets of Abha and Riyadh. The locally grown varieties were collected from different places in Jizan and Abha. Agaricus campestris was collected from a farm in Jizan. The collected samples were stored in containers and polythene bags. The samples were initially washed thoroughly with water to remove sand and any adhering substance and then preserved in formaldehyde solution for long term preservation. Photographs were taken at the sampling site and also in the laboratory. Samples were found in damp places of public gardens or on the decayed roots of the dead trees. The samples were photographed and collected from their natural sites and kept for laboratory identification (Abou-Zeid and Altalhi, 2006).

\section{Sample collection of imported varieties from different markets of Saudi Arabia}

Different markets of Abha and Riyadh were visited to collect the imported varieties. The collected samples were stored in containers and polythene bags. The samples were initially washed thoroughly with water and then preserved in formalin solution for long term preservation (Fig. 1-B).

\section{Macroscopic observation}

Identification was carried out by using standard manuals and keys to identification. Morphological characters along with gills structure and spores were used to identify. Transverse and longitudinal sections of the specimens were sliced to study the structure of the fruiting bodies.

\section{Results and discussion}

Nine different genera of mushrooms were collected from different areas of Jizan and Abha belonging to Ascomycotina and Basidiomycotina. The nine genera collected in the present study were Agaricus, Agrocybe, Amanita, Boletus, Coprinus, Lepiota, Pleurotus and Podaxis belonging to Basidiomycotina (Figs. 2). The mushroom, Morchella $s p$. is the only genus belonging to Ascomycotina (Fig. 2-H).

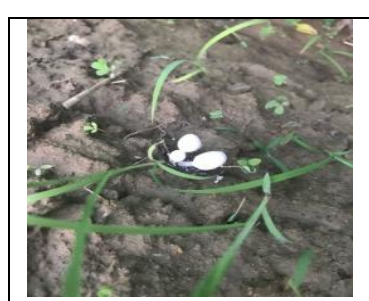
Naturally growing

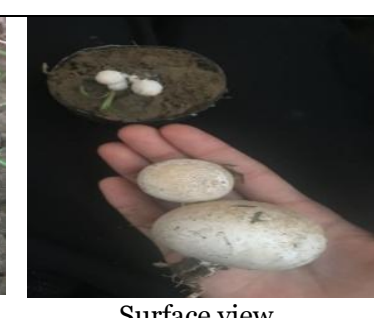

Surface view (A) Agaricus bisporous

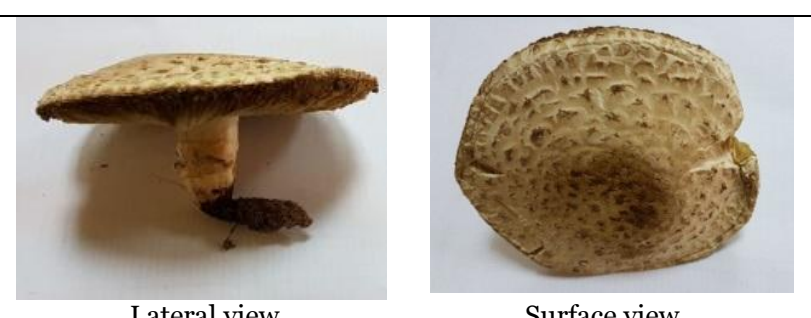

(B) Agaricus campestris

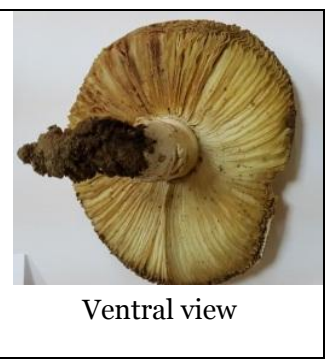

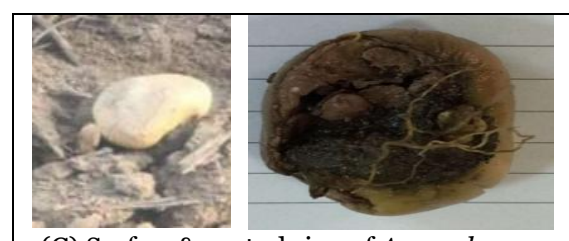

(C) Surface \& ventral view of Agrocybe sp.

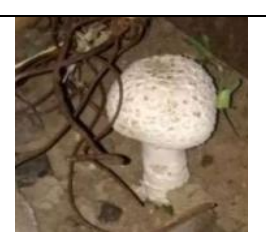

(D) Amanita sp.

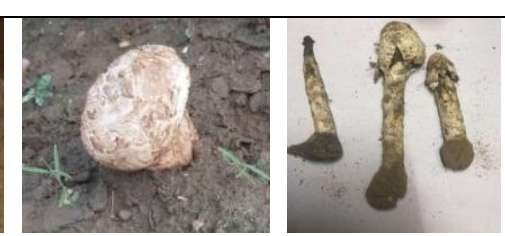

(E) Boletus sp.
(F) Coprinus sp.

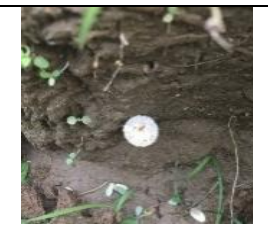

(G) Lepiota sp.

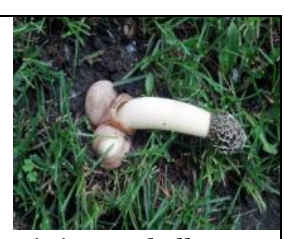

(H) Morchella sp.

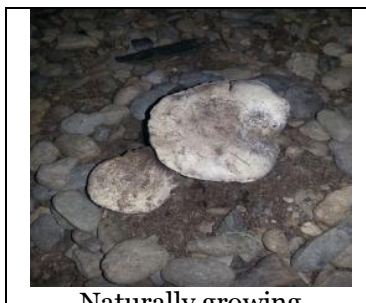

Naturally growing

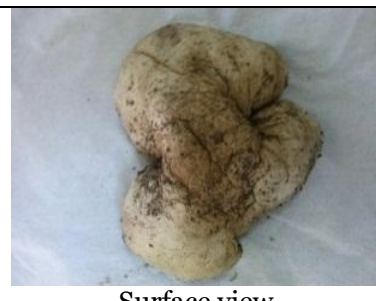

(I) Pleurotus ostreatus

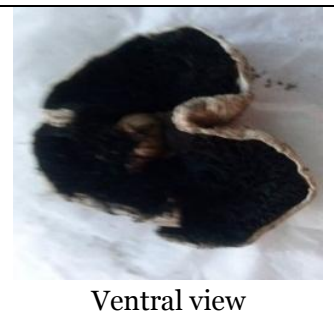

Ventral view

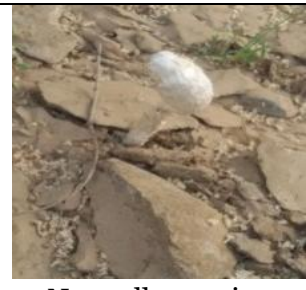

Naturally growing (J) Podoxis pistillaris

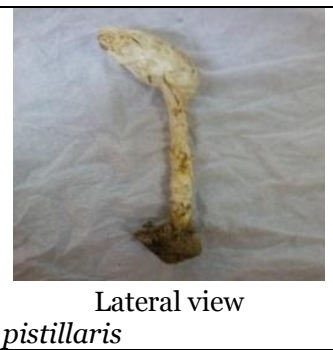

Fig. 2: Locally growing mushrooms from Abha and Jizan. 
The genus, Morchella Dill. The receptacle is pileate or clavate, impervious in the centre, stipitate, covered with hymenium, which is deeply folded and pitted (Taylor, 2010). The highest frequency of occurrence was recorded for Agaricus bisporus, Lepiota procera and L. rhacodes (Fig. 2). On the other hand, the rare existed species were Lepiota cristata, Pleurotus ostreatus and Boletus (AbouZeid and Altalhi, 2006). The imported mushrooms were collected from local markets from Abha and Riyadh. Eight genera of edible mushrooms imported from different countries which were identified as Agaricus bisporus with varieties like Silver Creek and Portobella from Malaysia, Auricularia polytricha (Black fungi) from Thailand, Cyclocybe aegerita (Yanagi mushroom) from Japan, Flamullina velutipes, Hypsizygus tessellates (White Crab Mushroom) from Thailand, Lentinula edodes (Shiitake Mushroom) from Holland, Lyophyllum shimeji (Brown Shimeji) from Thailand, Pleurotus (Oyster Mushroom) with two species, Pleurotus eryngii and Pleurotus ostreatus from Thailand (Fig. 3).

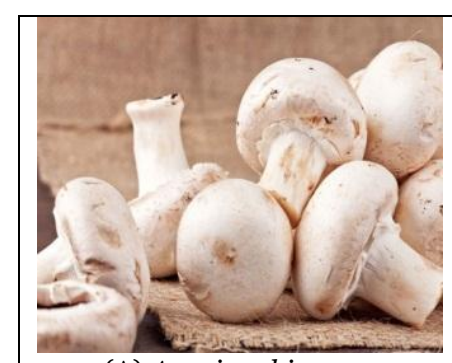

(A) Agaricus bisporus

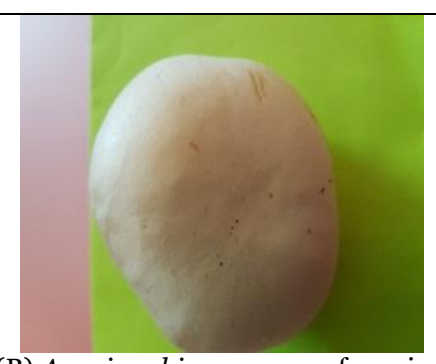

(B) Agaricus bisporus - surface view

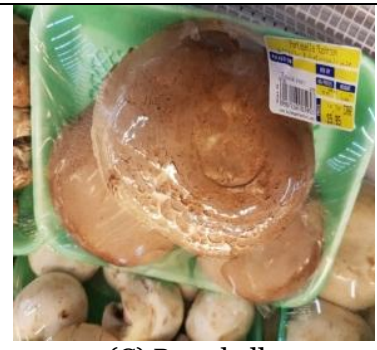

(C) Portobello

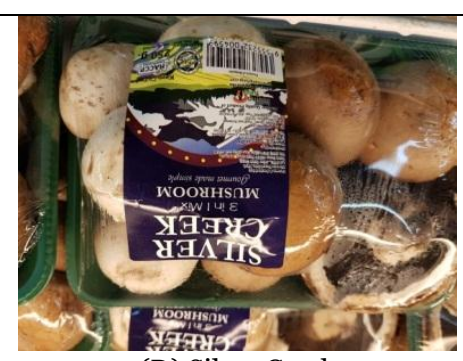

(D) Silver Creek

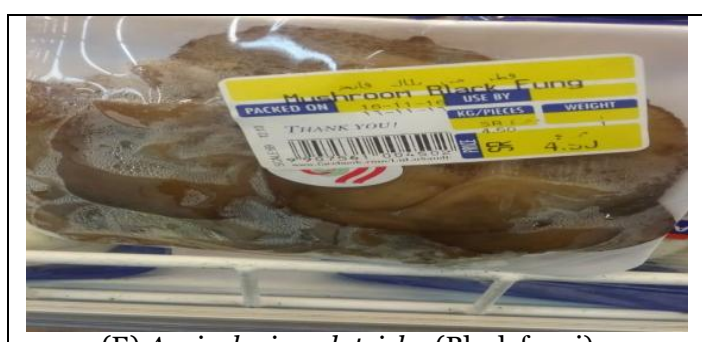

(E) Auricularia polytricha (Black fungi)

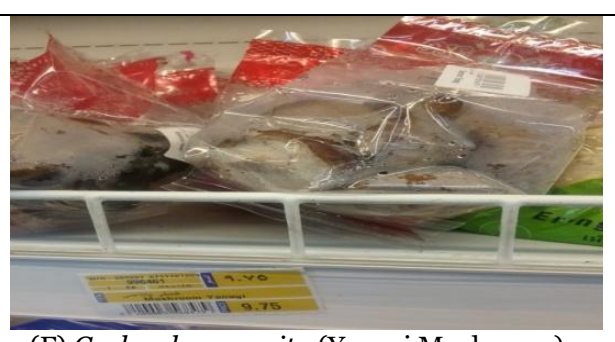

(F) Cyclocybe aegerita (Yanagi Mushroom)

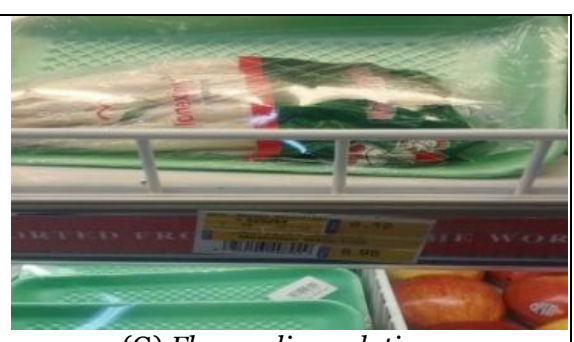

(G) Flammulina velutipes

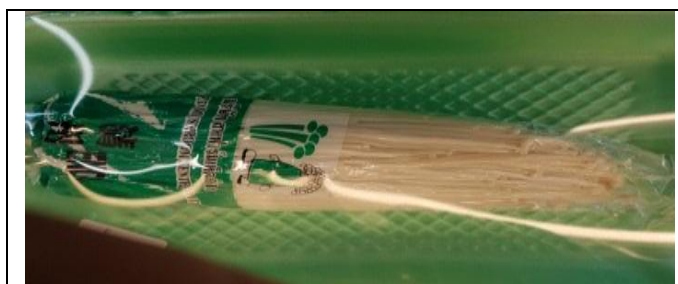

(H) Hypsizygus tessellates (White Crab Mushroom)

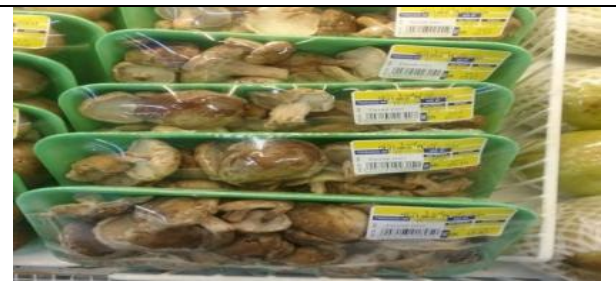

(I) Lentinula edodes (Shiitake Mushroom)

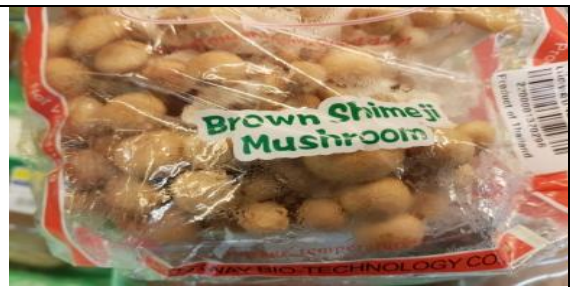

(J) Lyophyllum shimeji (Brown Shimeji)

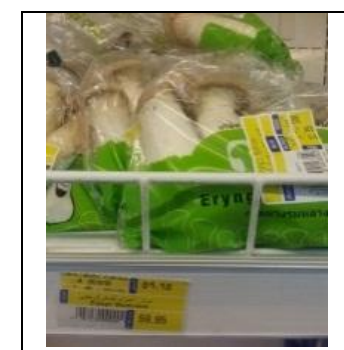

(K) Pleurotus eryngii

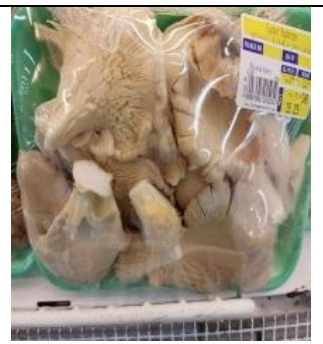

(L) Pleurotus ostreatus

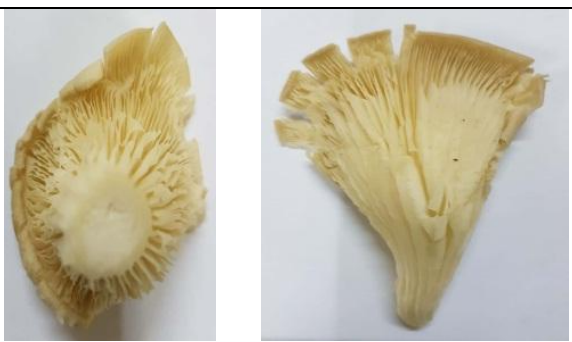

(M) Ventral view of Pleurotus ostreatus

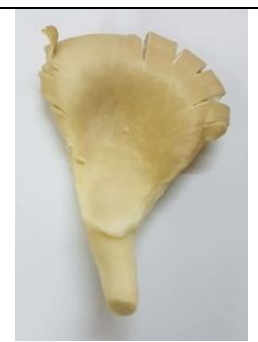

(N) Surface view of Pleurotus ostreatus

Fig. 3: Imported mushrooms from markets of Abha and Riyadh. 
The filter paper was folded twice and the mushroom inserted through a hole cut in the middle of the paper. The filter paper was pressed against the gills of the mushroom so that an impression of the gills is seen on the filter paper. The spore prints depicting the internal structure of the gills were taken from the freshly collected samples (Fig. 4).

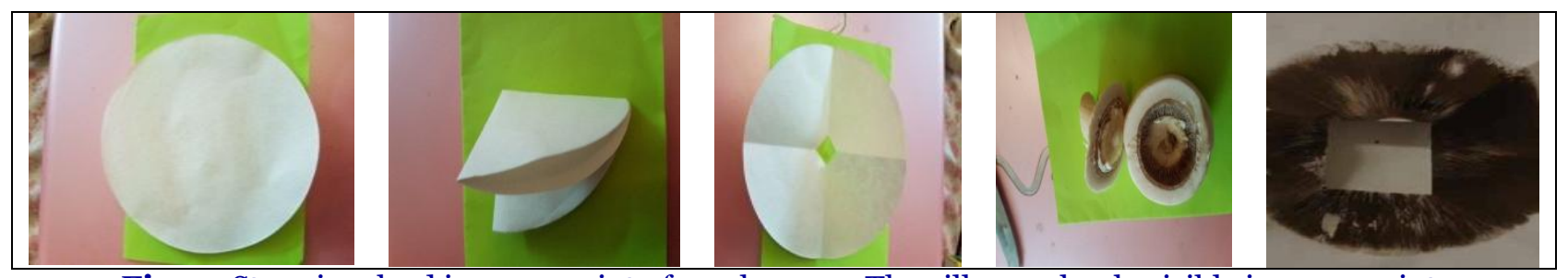

Fig. 4: Steps involved in spore print of mushrooms. The gills are clearly visible in spore print.

\section{Conclusion}

The edible mushrooms have high nutritional and medicinal values. The mushrooms are very beautiful to look at with a variety of colors and shapes. The present study focused on the collection and study of both the imported and locally grown mushrooms in Saudi Arabia. The different genera collected during this study are edible, taste good and have many health benefits. Hence the study is important because they can be grown in Saudi Arabia on large scale which can create job opportunities and improve the economy of the region.

\section{Conflict of interest statement}

Author declares that there is no conflict of interest.

\section{References}

Abou-Zeid, A. M., Altalhi, A. E., 2006. Survey of some mushrooms in Al-Taif Governorate of Saudi Arabia. World J. Agric. Sci. 2(1), 1-5.

Benchawattananon, R., 2016. Biodiversity of mushrooms in conservative forest in Dansai district of Loei Province, Thailand. Trop. Life Sci. Res. 27(Suppl.1), 103-109.

El Enshasy, H., Elsayed, E. A., Aziz, R., Wadaan, M. A., 2013. Mushrooms and truffles: Historical biofactories for complementary medicine in Africa and in the Middle East. Evidence-Based Compl. Alt. Med. 2013, Article ID 620451, 10 pages.

Identifying Edible and Poisonous Wild Mushrooms. https://www.wildfooduk.com/ mushroom-guide/

Taylor, T., 2010. Student's Hand-book of Mushrooms of America, Edible and Poisonous. Outlook Verlag GmbH, Frankfurt.

The Irish Times, 2018. Over 800 people suffer mushroom poisoning in Iran. 21 May 2018.

Verma, D., Chauhan, A., 2017. A Handbook of Mushroom Production in India. Lap Lambert Academic Publishing, 336p.

\section{How to cite this article:}

Manzelat, S. M., 2019. Mushrooms in Saudi Arabia (local and imported). Int. J. Curr. Res. Biosci. Plant Biol. 6(8), 8-12. doi: https://doi.org/10.20546/ijcrbp.2019.608.002 